\title{
A Study to Assess the Psychosocial Problems and Quality of Life Among Chronic Renal Failure Patients Undergoing Hemodialysis in Selected Hospital at Cuttack With a View to Develop an Information Booklet.
}

\author{
Mr. P. Arul Valan ${ }^{1}$ \\ ${ }^{I}$ (Vice Principal, College of Nursing Cuttack/ Utkal University, India) \\ (Research scholar, JJTU, Rajasthan)
}

\begin{abstract}
A study to assess the psychosocial problems and quality of life among chronic renal failure patients undergoing hemodialysis in selected hospital at Cuttack with a view to develop an information booklet. A descriptive survey approach was chosen for the study. Design selected for the present study is a Descriptive design. The study was conducted in dialysis unit of selected hospitals at Cuttack, Odisha, India. By using Purposive sampling technique 60 Dialysis patients who fulfilled the inclusion criteria were selected as samples. Demographic variable consisted of age, sex, area of living, occurrence of disease, co- morbid illness and number of dialysis. Data was collected among the dialysis patients based on WHOQOL tool. Majority of samples in the demographic profile of 28(46.67\%) of them were belong to the age group between 40 and 45 , $33(55 \%)$ of them were male, $30(50 \%)$ of them were urban population, 26(43.3\%) of them were taken 11- 20 number of cycle of dialysis, 20 (33.34\%) of them were had illness since 4- 8 years, 30(50\%) of them were having hypertension and renal diseases as co-morbid illness. The results of the study showed that most of the samples 27 (46.67\%), Moderate QOL, 20(33.3\%) Had poor QOL and remaining 12(20\%) good QOL among the 60 patients underwent hemodialysis. The findings regarding the domain of WHOQOL tool are assessed and findings revealed that hemodialysis patients had effects on their social relationship and environment significantly. The values of the table were found to pass the normality distribution test. HD patients indicated lower QOL scores in the domains of environment, social relationships and over all domain which respectively 0.02, 0.00 and 0.03 $(P<0.05)$, this indicated that patients with ESRD with Hemodialysis had their unpleasant quality of life based on social relationship and environment which affects their overall Quality of life.
\end{abstract}

Keywords: ESRD-End stage renal Disease, HD-Hemodialysis, QOL- Quality of life, WHO- world health organisation

\section{Introduction}

Generation today is very different from the past years. Many things are invented in terms of food, technology and other things that make a lot of people to live in luxury. But along these, in terms of the health of the people nowadays, there are certain diseases that are quite making a name in the statistical data of our health department. Due to sedentary life style, stress from daily living and lack of healthy activities, numerous people are now suffering from certain diseases. One common disease in this present time is kidney failure. Chronic renal failure is a silent epidemic of $21^{\text {st }}$ century. Its occurrence is universal. Hemodialysis is the most common method used to treat advanced and permanent kidney failure. Hemodialysis imposes a variety of physical and psychosocial stressors that challenge patients.

ESRD has a significant impact upon the lives of suffers. The experience of multiple losses, including kidney function, family role, work role, sexual function, time and mobility, impact significantly on the lives of patients. Further, including medication effects, dietary constraints, fear of death and dependency upon treatment, may affect quality of life and exacerbate feelings of loss of control. It has been widely claimed that depression is the most common psychological condition among patients with ESRD. While prevalent, depression and anxiety is still often unrecognized, reflecting a lack of routine psychology evaluation among this patient population. The consequences of missing depression among dialysis patients are considerable. Co morbid depressive illnesses amplify the impact of chronic illnesses, and increase functional disability and the use of health care services.

Renal disease is growing rapidly in India because of the high prevalence of diabetes and heart disease, which is the root cause of ESRD, the mean age of ESRD patients in India, is between 32 and 42 years, compared to 60 and 63 years in developed countries.

The individuals with end-stage renal disease (ESRD) undergoing dialysis experience increased levels of anxiety and depression. Anxiety and depression are known causes of morbidity among patients with chronic illnesses. Anxiety is an alerting signal, it warns of threat, external or internal and it is probably the life saving more than once in a life time. Majority of patients undergoing hemodialysis were depressed. Major risk factors 
for depression were marital status, illiteracy, number of children, socioeconomic factors, gender, hypertension and hypoalbuminemia. Depression is the most important under lying problem in the suicidal ideation and behaviour of dialysis patients. Depression in dialysis patients is often the result of the combined psychological and social impairments associated with the treatment of ESRD.

Approximately $13 \%$ of the world wide populations have renal disease that leads to chronic renal failure, current estimates suggests that 1.6 million individuals worldwide undergo maintenance dialysis. In India the appropriate prevalence of end stage renal disease (ESRD) is 800 per million population (pmp) and incidence of ESRD is $150-200 \mathrm{pmp}$ and currently $8.5 \mathrm{pmp}$ are undergoing hemodialysis.

The population of India exceeds one billion and is projected to become the major reservoir of chronic diseases like diabetes and hypertension. Since $25-40 \%$ of these subjects may develop Chronic Kidney Disease (CKD), the End-Stage Renal Disease (ESRD) burden will rise and the health care system would need to take care of them. The problems faced by hemodialysis patients are many. The survival of these patients may depend on dialysis and transplantation which is expensive, time consuming and poses a lot of psychosocial problems.

A study conducted to screen the psychosocial problems in 9382 hemodialysis patients from 12 countries, overall prevalence of physician-diagnosed depression was $13.9 \%$. Other psychological problems seen in these patients are anxiety, sexual dysfunctions, problems connected with difficulties in rehabilitation, the problem of the 'uncooperative' patients, and psychosis. Vigilant attention is required so that diagnosis may be made early and treatment started soon thereafter. Important methods of treatment are supportive psychotherapy, behavioral techniques for sexual dysfunctions, and the use of psychologically active drugs.

The investigator feels that, depression, anxiety and other physical problems may sometimes be hidden behind an array of vague symptoms and it becomes necessary to carefully assess the H.D. patients to identify marked depression and anxiety to treat the patient holistically. This will enable heath care professional in preventing the psychological problems and controlling the problems related to depression and anxiety. Mild level of depression can be identified and treated in time to permit it before in becomes severe. The investigator also feels that it is necessary to give attention to assessing the coping style of patients receiving hemodialysis to assist them in using a positive coping method. Hence there is need for considering the emotional status of haemodialysis patients and coping style when they are treated in the hospital or day care centre. This motivated the investigator to conduct the study to assess the level of anxiety, depression, physical problems and coping among haemodialysis patients who admitted in hospital.

\section{Objectives of The Study}

1. To assess the level of psychosocial problems among chronic renal failure patients undergoing hemodialysis.

2. To assess the quality of life among chronic renal failure patients undergoing hemodialysis.

3. To correlate the psychosocial problems and quality of life among chronic renal failure patients undergoing hemodialysis.

4. To associate the level of psychosocial problems and quality of life among chronic renal failure patients undergoing hemodialysis with their selected demographic variables.

\section{Methods}

A descriptive survey approach was chosen for the study. The research design selected for the present study is a Descriptive design. This study was conducted in dialysis unit of selected hospitals at Cuttack, Odisha, India. By using Purposive sampling technique 60 Dialysis patients who fulfilled the inclusion criteria were selected as samples. Demographic variable consisted of age, sex, area of living, occurrence of disease, comorbid illness and number of dialysis.

\section{Data Collection Procedure}

The data collection period was 4 weeks. Prior Permission was obtained from the Management of selected hospitals Dialysis unit to conduct the study. Good rapport was established and brief introduction about the study was given. The participants were assured that there is no physical or emotional harm during the data collection. 60 patients were selected by purposive sampling technique. Then data was collected by using World Health Organization Quality of Life instrument (WHOQOL-BREF) It is a self-report generic QOL inventory of 26 items, validated within Dialysis patients. The items fall into 4 domains: a) Physical health, b) Psychological well-being, c) Social Relationships, and d) Environment. Two of the items provide a facet measuring Overall QOL/health. It is rated on a 5-point Likert scale and the range of scores is between 1 and 20 with higher scores indicating better QOL.

\section{Ethical Consideration}

All patients had been informed of their rights to refuse or discontinue participation in the study, according to the ethical standards. Ethical permission for the study was obtained from the scientific committees of the hospitals. 


\section{Data Analysis}

Data analysis is the systematic organization of research data and the findings of the results using these data the data obtained were analyzed by using both descriptive and inferential statistics on the basis of the objectives and hypothesis of the study. Demographic data containing sample characteristics were analyzed using frequency and percentage.

\section{Results And Discussion}

Majority of samples in the demographic profile of $28(46.67 \%)$ of them were belong to the age group between 40 and $45,33(55 \%)$ of them were male, $30(50 \%)$ of them were urban population, $26(43.3 \%)$ of them were taken 11- 20 number of cycle of dialysis, 20 (33.34\%) of them were had illness since $4-8$ years, 30(50\%) of them were having hypertension and renal diseases as co-morbid illness.

The findings showed that most of the samples 27 (46.67\%), Moderate QOL, 20(33.3\%) Had poor QOL and remaining $12(20 \%)$ good QOL among the 60 patients underwent hemodialysis. The findings regarding the domain of WHOQOL tool are assessed and findings revealed that hemodialysis patients had effects on their social relationship and environment significantly

\section{Figures And Tables}

TABLE: 1 Frequency percentage distribution of overall Quality of life among hemodialysis patients based on WHOQOL tool

$\mathbf{N}=60$

\begin{tabular}{|l|l|l|l|}
\hline S.No & QOL Of HD patients & Frequency & Percentage \\
\hline 1 & Poor & 20 & 33.3 \\
\hline 2 & Moderate & 28 & 46.67 \\
\hline 3 & Good & 12 & 20 \\
\hline
\end{tabular}

The findings showed that most of the samples 27 (46.67\%), Moderate QOL, 20(33.3\%) Had poor QOL and remaining $12(20 \%)$ good QOL among the 60 patients underwent hemodialysis.

TABLE: II Mean, SD of WHOQOL domains and the overall Quality of life among hemodialysis patients $\mathbf{N}=60$

\begin{tabular}{|l|l|l|l|l|}
\hline S.No & Domains & Mean & SD & 'P'value \\
\hline 1 & Physical & 12.71 & 3.7 & 0.08 \\
\hline 2 & Psychological & 13.26 & 3.65 & 0.86 \\
\hline 3 & Social relationship & 12.89 & 3.51 & $0.02^{*}$ \\
\hline 4 & Environment & 13.00 & 2.71 & $0.00^{*}$ \\
\hline 5 & Over all & 12.86 & 3.45 & $0.03^{*}$ \\
\hline
\end{tabular}

\section{$\mathbf{P}<0.05$ significant}

The values of the table were found to pass the normality distribution test. HD patients indicated lower QOL scores in the domains of environment, social relationships and over all domain which respectively 0.02 , 0.00 and $0.03(\mathrm{P}<0.05)$, this indicated that patients with ESRD with Hemodialysis had their unpleasant quality of life based on social relationship and environment which affects their overall Quality of life.

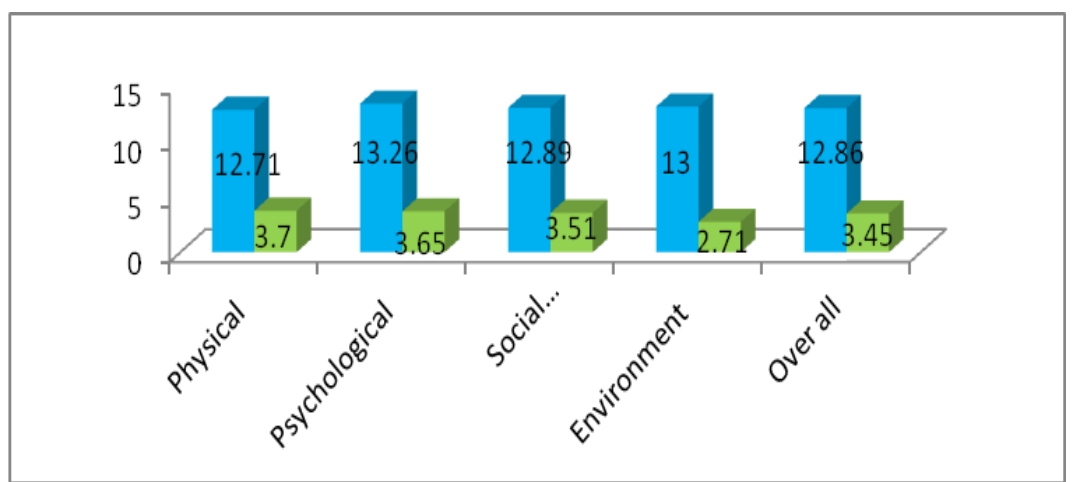

Figure: 1 Mean, SD of WHOQOL domains and the overall Quality of life among hemodialysis patients.

\section{Conclusion}

The results of the study showed that most of the samples 27 (46.67\%), Moderate QOL, 20(33.3\%) Had poor QOL and remaining 12(20\%) good QOL among the 60 patients underwent hemodialysis. The findings regarding the domain of WHOQOL tool are assessed and findings revealed that hemodialysis patients had effects on their social relationship and environment significantly. The values of the table were found to pass the 
normality distribution test. HD patients indicated lower QOL scores in the domains of environment, social relationships and over all domain which respectively $0.02,0.00$ and $0.03(\mathrm{P}<0.05)$, this indicated that patients with ESRD with Hemodialysis had their unpleasant quality of life based on social relationship and environment which affects their overall Quality of life.

\section{Implications for nursing education}

The nurse educator has to encourage the nurses to give importance for patient's psychosocial aspects also while taking care of patients with Hemodialysis.

1. As a result of increasing number of incidence education program can be given to the patients regarding coping strategies.

2. Nurses should have adequate knowledge regarding care of patients undergoing hemodialysis.

\section{Implications for nursing practice}

1. The finding of the study will help nurses to plan to improve the QOL of patients undergoing hemodialysis.

2. Nurses can easily communicate with the patients admitted in hospital so that they can help to improve the patients QOL.

\section{Implications for nursing research}

1. Nursing research can be done in the areas of various coping mechanisms and exercise program for the hemodialysis patients

\section{Recommendations for further research}

In the view of the findings and limitations of the present study following recommendations are offered for further research.

1. A study can be conducted to assess the practice of various coping strategies.

2. A study can be done to assess the lifestyle modification program after renal diseases.

\section{References}

[1]. Demura S, Sato S. Relationships between depression, lifestyle and quality of life in the community dwelling elderly: a comparison between gender and age groups. J Physiol Anthropol Appl Human Sci 2003;22(3):159-166.

[2]. Nilsson J, Rana AK, Kabir ZN. Social capital and quality of life in old age: results from a cross-sectional study in rural Bangladesh. J Aging Health 2006;18(3):419-434.

[3]. Borglin G, Jakobsson U, Edberg AK, Hallberg IR. Older people in Sweden with various degrees of present quality of life: their health, social support, everyday activities and sense of coherence. Health Soc Care Community 2006;14(2):136-146.

[4]. Gokal R. Quality of life. In: Gokal R, Khanna R, Krediet RTh, Nolph E. (eds). The Textbook of Peritoneal Dialysis. Dordrecht: Kluwer Acad Publ, 1994.

[5]. Gokal R. Quality of life in patients undergoing renal replacement therapy. Kidney Int Suppl 1993;40:S23-27.

[6]. Kimmel PL, Peterson RA, Weihs KL, Simmens SJ, Boyle DH, Cruz I, Umana WO, et al. Aspects of quality of life in hemodialysis patients. J Am Soc Nephrol 1995;6(5):1418-1426.

[7]. Griva K, Newman S. Quality of life in end-stage renal disease and treatments. In: Anagnostopoulos F, Karademas E. (eds). Special Issues in Health Psychology. A Greek Perspective. Athens: Livani, 2007.

[8]. Diaz-Buxo JA, Lowrie EG, Lew NL, Zhang H, Lazarus JM. Quality-of-life evaluation using Short Form 36: comparison in hemodialysis and peritoneal dialysis patients. Am J Kidney Dis 2000;35(2):293-300.

[9]. Wu AW, Fink NE, Marsh-Manzi JV, Meyer KB, Finkelstein FO, Chapman MM, Powe NR. Changes in quality of life during hemodialysis and peritoneal dialysis treatment: generic and disease specific measures. J Am Soc Nephrol 2004;15(3):743-753.

[10]. Merkus MP, Jager KJ, Dekker FW, Boeschoten EW, Stevens P, Krediet RT. Quality of life in patients on chronic dialysis: selfassessment 3 months after the start of treatment. The Necosad Study Group. Am J Kidney Dis 1997;29(4):584-592

[11]. Mittal SK, Ahern L, Flaster E, Mittal VS, Maesaka JK, Fishbane S. Self-assessed quality of life in peritoneal dialysis patients. Am J Nephrol 2001;21(3):215-220.

[12]. Oikonomidou G, Zlatanos D, Vayopoulos H, Hatzidimitriou H. Depression in patients with chronic renal failure. Dialysis Living 2005;14:22-32.

[13]. Bradley C, McGee H. Improving quality of life in renal failure: ways forward. In: McGee H, Bradley C. (eds). Quality of life following renal failure. Chur: Harwood Academic Publishers, 1994.

[14]. Hooper G. Psychological care of patients in the renal unit. In: McGee H, Bradley C. (eds). Quality of life following renal failure. Chur: Harwood Academic Publishers, 1994.

[15]. Theofilou P. The role of sociodemographic factors in health-related quality of life of patients with end-stage renal disease. International Journal of Caring Sciences 2011;4:40-50.

[16]. Oo TN, Roberts TL, Collins AJ. A comparison of peritonitis rates from the United States Renal Data System database: CAPD versus continuous cycling peritoneal dialysis patients. Am J Kidney Dis 2005;45(2):372-380.

[17]. Yucedal C, Olmez N, Gezen G, Celik F, Altindag A, Yilmaz ME, Kara IH. Depression in renal dialysis patients. Edtna Erca Journal 2003;3:160-164.

[18]. Karamanidou C, Theofilou P, Ginieri-Coccossis M, Synodinou C, Papadimitriou G. Anxiety, depression and health beliefs in endstage renal disease (ESRD) patients. 17th European Congress of Psychiatry. Lisbon, 2009; Abstract R38. 